\title{
BIOMONITORING OF SEVOFLURANE EXPOSURE IN ANESTHESIOLOGIST
}

\author{
Firly Ratsmita ${ }^{1}$ Muhammad Ilyas $^{2}$ \\ ${ }^{1}$ Departement of Community Medicine, Medical Faculty,University of Indonesia, Indonesia \\ ${ }^{2}$ Occupational Environmental Health and Research Center IMERI FKUI, Indonesia \\ Correspondence Address: Firly Ratsmita \\ Email: firly.ratsmita@ui.ac.id
}

\begin{abstract}
Sevoflurane is used by anesthetists for the induction and maintenance of general anesthesia. This causes the anesthetist to get daily exposures. This will be a potential hazard for exposed operating room personnel, especially anesthetists. The adverse health effects of sevoflurane as hepatotoxic, nephrotoxic and neurotoxic in the human body can be a risk for anaesthetists. Biological monitoring can be done by measuring the levels of sevoflurane and its metabolites or by looking at biomarkers for their effects on health effects. The aim of this study was to seek a literature review on the biomonitoring of sevoflurane exposure in anaesthetists. We searched the literature review using the PRISMA method in PubMed and Google scholar using the following keywords "occupational disease" "chronic effects" "anaesthetist" "sevoflurane exposure" "inorganic fluoride" "biomarkers" previously using the term MeSH and combined with Boolen "OR" and AND". We obtain 75 articles taken from the database, excluded 35 articles, and selected 5 articles. The results of the review articles showed that there were health effects, especially on liver and kidney function in chronic exposure. Biological monitoring can be undertaken by detecting sevoflurane and its metabolites in the urine during work and function of the liver and kidneys. The evidence for biological monitoring as surveillance in anaesthesiologists remain inconsistent due to limited studies. We recommend to measure sevoflurane in ambient air using a hierarchy of controls, such as elimination, replacement, engineering, administrative and personal protective equipment. We need to undertaken environmental and biological monitoring in order to acquire a safe and healthy work environment.
\end{abstract}

Keywords: sevoflurane exposure, occupational health, anesthesiologist

\section{INTRODUCTION}

Prior to the invention of intravenous drug administration, the first anaesthetics (diethyl ether) were delivered through inhalation and used as a general anaesthetic by Long in the 1840s. Classification of inhaled anaesthetic drugs are ethers, alkanes, and gases. The drugs have an unconscious and immobile effect in patient. The pharmacokinetic of drugs relies on their physical properties. Most of the absorption of inhalation anaesthetics and the rate of elimination from the alveoli are determined by solubility in blood where the soluble substance has a faster rate than the less soluble substance. The effect of inhalation anaesthetics depends on the alveolar concentration not on the dose of the anesthetic absorbed. Wells first used nitrous oxide in 1844 for dental analgesia, and chloroform (trichloromethane) was developed by Simpson in 1847 as a nonexplosive alternative to ether. These medicines, of which only nitrous oxide is still commonly used, dominated the first century of anaesthesia. Ethers include diethyl ether, methoxy propane, vinyl ether, enflurane, methoxyflurane, isoflurane, sevoflurane, and desflurane (Hemmings and Egan, 2019).

Sevoflurane, a halogenated inhalational anaesthetic, used for the induction and maintenance of general anaesthesia in adult and paediatric patients that more than 20 years. The character of sevoflurane is volatile, non-flammable, non-irritant, and easy to provide, with low solubility profile and blood-to-gas partition coefficient (Brioni et al., 2017).

Sevoflurane, a fluorinated methyl isopropyl ether has very poor blood solubility. Sevoflurane is a volatile anaesthetic with smells sweet and 
minimally pungent that used during surgical procedures offers hypnosis, amnesia, analgesia, akinesia, and autonomic blockade. Sevoflurane causes modern agents with the least cerebral vasodilation, thus it is favourable in neurosurgical patients with elevated intracranial pressure (Edgington, Muco and Maani, 2007; Hemmings and Egan, 2019).

Inhaled anaesthetics can result in brain damage that can be a trigger the onset of Alzheimer's disease. It can be a potential risk factor for cognitive decline. Inhaled anaesthetics in human cell cultures cause amyloid $\beta$ accumulation and cell death, suggesting a possible molecular mechanism of cognitive decline related to anaesthesia. The researchers found that more plaques were created by the transgenic mice exposed to inhalation anaesthetics (Kubota, 1992; İnan and Özköse Şatirlar, 2015).

Sevoflurane triggers health effects in high and low concentrations. Headache, fatigue, disorder coordination, liver and kidney disease are common symptoms that occur at high concentrations. Generally, chronic effects with small concentrations do not cause health problems. However, several study showed the relationship between the incidence of miscarriage, genetic mutations, and cancer among workers in the operating room. In addition, workers exposed to anaesthetic gases have an increased incidence of chronic headaches, peripheral neuropathy, anemia , multiple sclerosis and depression (Dalagkozi et al., 2018).

The main effects of sevoflurane exposures are nephrotoxic, hepatotoxic, and neurotoxic. The aim of this review is to provide an understanding to the specific biological monitoring and systemic health effect of sevoflurane exposure in anaesthesiologist.

\section{METHOD}

We undertook the literature searching strategies for answering the clinical question performed on December 14, 2020 with the PRISMA method that used electronic database in Google Scholar and PubMed. Keywords used were "chronic effect of sevoflurane for occupational disease" and "biomarker of sevoflurane exposure in anaesthesiologist" in google scholar. Keywords in PubMed has been used "occupational disease" "chronic effect" "anaesthesiologist" "sevoflurane exposure" "inorganic fluoride" "biomarker" which previously used the MeSH term and combined with Boolen operation "OR" and "AND". Our goal was to find answers to the question 'What is the specificity of biological monitoring and health effect in anaesthesiologist with sevoflurane exposure.

Table 1. Searching strategy using database from PubMed and Google Scholar

\begin{tabular}{|c|c|c|c|}
\hline Database & Keyword & Finding & Selected \\
\hline $\begin{array}{l}\text { Google } \\
\text { scholar }\end{array}$ & $\begin{array}{l}\text { chronic effect of sevoflurane for } \\
\text { occupational disease }\end{array}$ & 20 & 2 \\
\hline $\begin{array}{l}\text { Google } \\
\text { scholar }\end{array}$ & $\begin{array}{l}\text { biomarker of sevoflurane exposure in } \\
\text { anesthesiologist }\end{array}$ & 20 & 2 \\
\hline Pubmed & $\begin{array}{l}\text { Search ((((occupational disease) OR } \\
\text { chronic effect)) AND anesthesiologist) } \\
\text { AND (((((sevoflurane exposure) OR } \\
\text { inorganic flouride) OR inorganic } \\
\text { flouride[MeSH Terms]) OR biomarker }) \\
\text { OR biomarker[MeSH Terms]) }\end{array}$ & 35 & 1 \\
\hline
\end{tabular}


The inclusion criteria of this searching strategy were research in anaesthesiologist, occupational exposure, biomonitoring, full text article available. The exclusion criteria of this article were inaccessible articles. We critical appraisal article according to the systematic review, observational study, and case study. The authors concluded that this literature review did not require approval by the Ethics Committee.

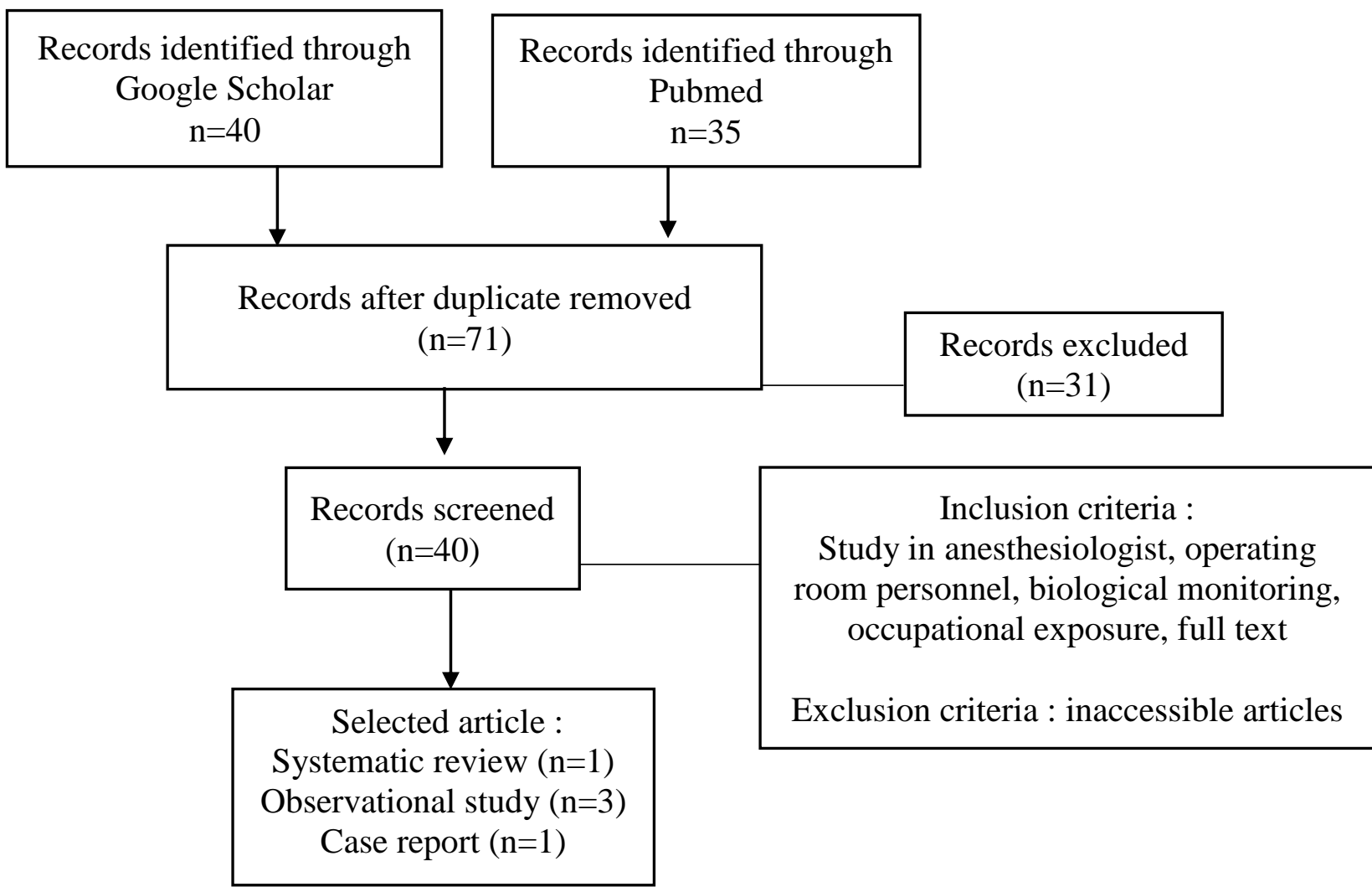

Diagram 1. Searching diagram on finding literatures

\section{RESULT}

A total of 75 articles were initially retrieved from online database. A total of 31 articles $(41 \%)$ were excluded because did not relate to the aims of study. The study was explained about the other inhaled anaesthetic agent without sevoflurane. We eliminated the article from abstract. Then, we screened the 40 article that have inclusion criteria like study in anaesthesiologist, operating room personnel, biological monitoring, occupational exposure, and full text.

Table 2. Critical appraisal systematic review

\begin{tabular}{ll}
\hline Appraisal question & Answer \\
$\begin{array}{l}\text { What was the issue PICO } \\
\text { in the systematic review? }\end{array}$ & $\begin{array}{l}\text { What is the impact of occupational exposure to volatile } \\
\text { anesthetics exposure and the best health surveillance for } \\
\text { exposed personnel? }\end{array}$ \\
$\begin{array}{l}\text { F- Is it doubtful that } \\
\text { important and substantial } \\
\text { studies have been } \\
\text { missed? }\end{array}$ & $\begin{array}{l}\text { Unclear, because only use } 2 \text { database, in the Medline and } \\
\text { Cochrane Library databases. }\end{array}$ \\
\hline
\end{tabular}


A- Are the criteria used to select articles appropriate?

\section{A- Do the included studies have good validity to answer the questions posed?}

T- Do have similar results from one study to another?

What is the results?
Unclear, inclusion study just only depend on title, language, and population like anesthetists, surgeons, nurses and auxiliary personnel

Unclear, because no specific information or resume of validation the study in this review

Yes

Evidence of the adverse effects on exposed workers of volatile anesthetics is contradictory since there is no evidence of adverse effects when the level of the monitoring environment is held below the legal threshold values. It is still very few reliable details exist in this systematic analysis and may involve reviewing and revising surveillance guidelines and procedures for exposed employees. No clinical signs or biomarkers have been established as appropriate for the use of exposed workers in surveillance.
A systematic review containing seventeen studies on the impact of sevoflurane was conducted by Molina Aragonés et al., 2016 to address their concern about the effect of occupational exposure to volatile anaesthetics and the best of health monitoring for exposed staff?' They found that sevoflurane exposure, depend on the dose, can adversely affect the liver and kidney. Some authors said that sevoflurane can make a DNA damage when the sevoflurane exposure in workplace above 4 ppm and no impact of DNA when the sevoflurane exposure under $0,5 \mathrm{ppm}$. They believe if the air monitoring level under of $2 \mathrm{ppm}$ would be the safety workplace. The effect of the currently used volatile anaesthetic on the population exposed has been routinely studied and very few reliable data have been collected. Therefore, review surveillance guidelines and procedures for exposed employees is unclear. No clinical sign or biomarker has been established as appropriate for use in surveillance in exposed staff (Molina Aragonés et al., 2016).

The other research involved anaesthesiologists in 52 operating room workers who had been randomly chosen for at least one year of exposure as a case group and fifty two administrative staff as a control group. The measure of outcome was concentrations of nitrous oxide, isoflurane, and sevoflurane in urine sampling that had taken in morning shift/ at least three hours of exposure in operating room. Liver and kidney function are calculated by mean levels of alanine aminotransferase, aspartate aminotransferase, alkaline phosphatase, gamma-glutamyl transferase, alpha-glutathione-s-transferase, and serum levels of kidney injury molecules-1, creatinine, and calcium (Neghab et al., 2020).

In the result of this study showed that the non exposed group have lower risk 
than the exposed group in aspartate aminotransferase ( $p$ value 0.04), alanine aminotransferase ( $\mathrm{p}$ value 0.01 ), gamma glutamyl transferase ( $\mathrm{p}$ value 0,003 ), alpha glutathione s-transferase ( $\mathrm{p}$ value 0.04 ), serum creatinine ( $p$ value 0.03 ), kidney injury molecule ( $\mathrm{p}$ value 0.003 ), calcium ( $\mathrm{p}$ value <0.001) (Neghab et al., 2020) .

Table 3. Critical appraisal observational study

\begin{tabular}{|c|c|c|c|c|c|c|c|c|c|c|}
\hline Articles & 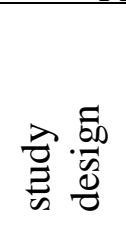 & 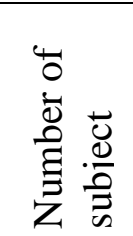 & 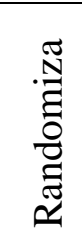 & 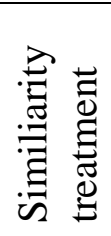 & $\stackrel{\stackrel{0}{\Xi}}{\stackrel{\Xi}{\Xi}}$ & 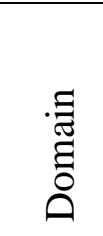 & 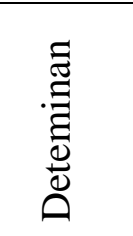 & $\begin{array}{l}\text { Measurement } \\
\text { of outcome }\end{array}$ & Result & 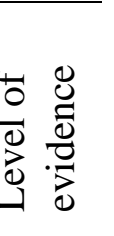 \\
\hline $\begin{array}{l}\text { Toxic } \\
\text { Responses } \\
\text { Of The } \\
\text { Liver And } \\
\text { Kidneys } \\
\text { Following } \\
\text { Occupatio } \\
\text { nal } \\
\text { Exposure } \\
\text { To } \\
\text { Anestheti } \\
\text { c Gases }\end{array}$ & $\begin{array}{l}\text { case } \\
\text { contr } \\
\text { ol }\end{array}$ & $\begin{array}{l}52 \\
\text { expos } \\
\text { ed and } \\
52 \\
\text { unexp } \\
\text { osed } \\
\text { group }\end{array}$ & $\begin{array}{l}\text { Ye } \\
\mathrm{s}\end{array}$ & $\begin{array}{l}\text { Ye } \\
\mathrm{s}\end{array}$ & $\begin{array}{l}\text { Un } \\
\text { cle } \\
\text { ar }\end{array}$ & $\begin{array}{l}\text { Pop } \\
\text { ulati } \\
\text { on at } \\
\text { risk } \\
\text { in } \\
\text { expo } \\
\text { sed } \\
\text { grou } \\
\text { p ( } \\
\text { oper } \\
\text { ating } \\
\text { roo } \\
\text { m } \\
\text { pers } \\
\text { onne } \\
\text { l) }\end{array}$ & $\begin{array}{l}\text { yes, as } \\
\text { in } \\
\text { practi } \\
\text { ce } \\
\text { (expos } \\
\text { ure/ } \\
\text { risk } \\
\text { factor) }\end{array}$ & $\begin{array}{l}\text { Yes, urinary } \\
\text { and blood } \\
\text { sampleuse the } \\
\text { same } \\
\text { equipment }\end{array}$ & $\begin{array}{l}\text { Exposed } \\
\text { group have } \\
\text { a higher } \\
\text { risk to renal } \\
\text { and liver } \\
\text { function } \\
\text { than } \\
\text { unexposed } \\
\text { group }\end{array}$ & 1 \\
\hline $\begin{array}{l}\text { Biomonit } \\
\text { oring } \\
\text { occupatio } \\
\text { nal } \\
\text { sevofluran } \\
\text { e } \\
\text { exposure } \\
\text { at low } \\
\text { levels by } \\
\text { urinary }\end{array}$ & $\begin{array}{l}\text { Obse } \\
\text { rvati } \\
\text { onal } \\
\text { study }\end{array}$ & $\begin{array}{l}\text { Indivi } \\
\text { dual } \\
\text { sevofl } \\
\text { urane } \\
\text { expos } \\
\text { ure }\end{array}$ & $\begin{array}{l}\text { Un } \\
\text { cle } \\
\text { ar }\end{array}$ & $\begin{array}{l}\text { Ye } \\
\mathrm{s}\end{array}$ & $\begin{array}{l}\text { Un } \\
\text { cle } \\
\text { ar }\end{array}$ & $\begin{array}{l}\text { Pop } \\
\text { ulati } \\
\text { on at } \\
\text { risk }\end{array}$ & $\begin{array}{l}\text { Yes, } \\
\text { as in } \\
\text { practi } \\
\text { ce } \\
\text { (expos } \\
\text { ure/ }\end{array}$ & $\begin{array}{l}\text { Yes, the } \\
\text { passive air } \\
\text { sampling } \\
\text { device } \\
\text { Radiello, and } \\
\text { assaying Sev- }\end{array}$ & $\begin{array}{l}\text { In this } \\
\text { research, } \\
\text { the } \\
\text { exposure } \\
\text { biomarker } \\
\text { (urinary } \\
\text { sevoflurane } \\
\text { and } \\
\text { hexafluoroi } \\
\text { sopropanol) }\end{array}$ & ) \\
\hline Articles & 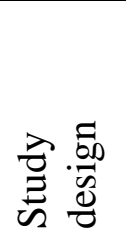 & 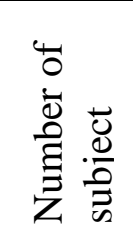 & 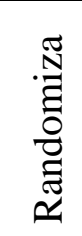 & 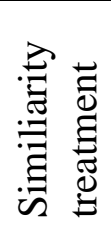 & 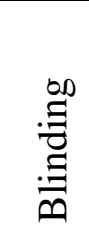 & 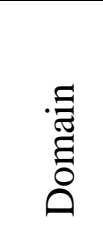 & 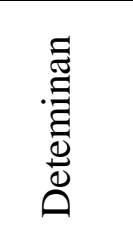 & $\begin{array}{l}\text { Measurement } \\
\text { of outcome }\end{array}$ & Result & 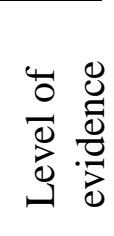 \\
\hline $\begin{array}{l}\text { sevofluran } \\
\text { e and } \\
\text { hexafluor } \\
\text { oisopropa } \\
\text { nol }\end{array}$ & & $\begin{array}{l}r \text { was } \\
\text { measu } \\
\text { ed in } \\
100 \\
\text { health } \\
\text { care } \\
\text { operat } \\
\text { ors }\end{array}$ & & & & & $\begin{array}{l}\text { risk } \\
\text { factor }\end{array}$ & $\begin{array}{l}\mathrm{U} \text { and HFIP } \\
\text { concentration } \\
\text { s. The } \\
\text { environmenta } \\
1 \text { levels of } \\
\text { sevoflurane } \\
\text { in workplace }\end{array}$ & $\begin{array}{l}\text { used to } \\
\text { assess } \\
\text { occupation } \\
\text { al exposure } \\
\text { to } \\
\text { sevoflurane } \\
\text { has been } \\
\text { found to }\end{array}$ & \\
\hline
\end{tabular}




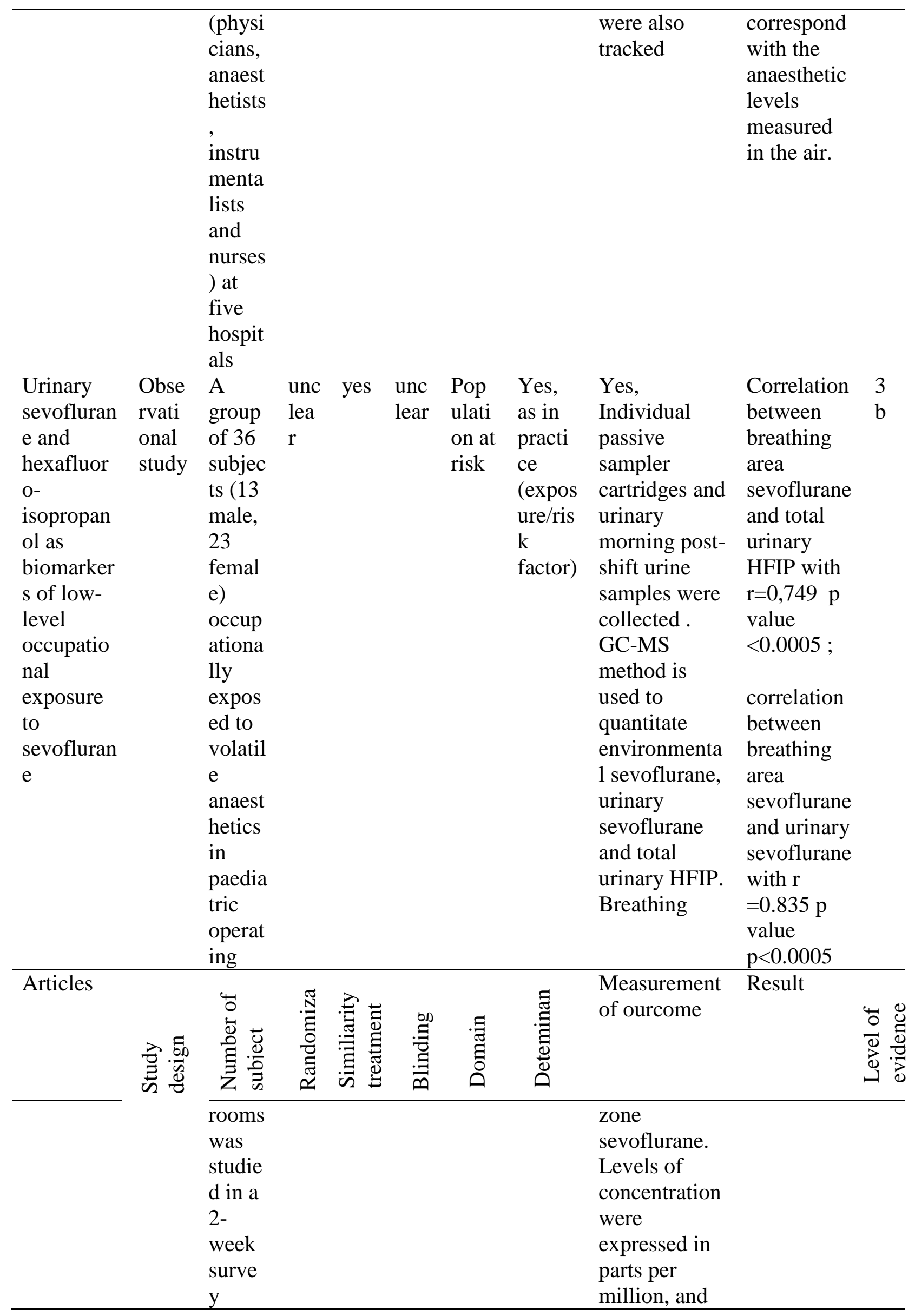




\begin{tabular}{ll}
\hline analyte urine \\
concentration \\
s were \\
expressed in \\
micrograms \\
per liter of \\
urine and in \\
milligrams \\
per liter of \\
urine (for \\
sevoflurane \\
and HFIP)
\end{tabular}

In order to evaluate and analyze the best biomarker of exposure to sevoflurane, Maria et al have examined the relationship of sevoflurane levels with urinary concentration or hexafluoroisopropanol (HFIP) with the corresponding biological equivalent exposure limit values. The measure applied to 100 healthcare in operating room in five hospitals in northeastern Italy who were exposed to sevoflurane by passive air sampling in breathing zone personnel and by assessing the levels of Sev-U (sevoflurane-urine) and HFIP in urine sampling obtained at the end of shift work in operating room (Scapellato et al., 2014).

Gas chromatography-mass spectrometry was used for their research. They reported very low levels in personal exposure, typically under $0.5 \mathrm{ppm}$ (mean $0.116 \mathrm{ppm}$; range $0.007-0.940 \mathrm{ppm}$ ), as a result. The concentrations of sevoflurane (Sev-U) and HFIP from urine sampling were between $0.1-17.28 \mathrm{mg} / \mathrm{L}$ and $5-550$ $\mathrm{mg} / \mathrm{L}$, respectively. There was a statistically important association between the two biomarkers and workplace exposure levels (Sev-U, r=0.49; HFIP, $\mathrm{r}=0.52$ ), but there was an abnormal distribution of value. Sevoflurane in urine (Sev-U values) appears to be affected at the end of the shift as a peak value of exposure, while HFIP on the day before. In conclusion, both Sev-U and HFIP are suitable biomarkers to determine the exposure of sevoflurane in this analysis (Scapellato et al., 2014).

Antonio et al studied in 36 subjects (13 male, 23 female) occupationally exposed to volatile anaesthetics in paediatric operating rooms in a 2-week survey. The objective of the study is to quantify environmental sevoflurane, urinary sevoflurane and total urinary HFIP, using a previously mentioned GC-MS technique such as Maria et al (Accorsi et al., 2005).

Table 3. Critical appraisal for case studies

\begin{tabular}{ll}
\hline Appraisal questions & Answer \\
\hline $\begin{array}{l}\text { Does the research answer the problem } \\
\text { clearly? }\end{array}$ & $\begin{array}{l}\text { Yes. Responding to anesthetic gas exposure as a } \\
\text { potential risk of Parkinson's Disease (PD) }\end{array}$ \\
$\begin{array}{ll}\text { Is the study design appropriate for } \\
\text { answering research questions?? }\end{array}$ & $\begin{array}{l}\text { Yes. } \\
\text { The results of hexafluoroisopropanol was 483.4 } \\
\mu \mathrm{g} / \text { liter (over the } 465 \mu \mathrm{g} / \text { liter threshold) in May 2007 } \\
\text { and } 535.6 \mu \mathrm{g} / \text { liter on next week. }\end{array}$ \\
\end{tabular}




\begin{tabular}{ll}
\hline Are the background and subject criteria & Yes, The subject has worked as a anesthesiologist for \\
related to the population to be & 30 years, exposing nitrous oxide for 22 years and \\
referenced? & sevoflurane for 23 years.
\end{tabular}

Is the researcher's perspective clearly explained??

Is the data collection method clear??

Do the methods for analyzing data have good validity and are reliable? Are there any quality control measures??

Was the analysis repeated by more than one researcher to ensure reliability?

Are the results credible, and if so, are they relevant to the practitioner?

Are the conclusions drawn justified by the results?

Can the study findings be used in different practitioners?

Sevoflurane concentration levels in the breathing zone were expressed in ppm and analyte urine concentrations were expressed in mcg dan mg per litre of urine (sevoflurane and HFIP). There was a correlation between sevoflurane breathing area and total urinary HFIP with a p-value of $r=0.749<0.0005$; correlation between sevoflurane breathing area and urinary sevoflurane with a $\mathrm{p}$-value of $\mathrm{r}=0.835$ $\mathrm{p}<0.00055$ (Accorsi et al., 2005).

A case was underwent by an anaesthesiologist, 59 years old, and 23 years exposed to sevoflurane. The absence
Yes. Differential diagnosis is also considered. Sevoflurane has been shown to increase TNF-alpha and beta-amyloid development by activating caspases and apoptotic cascades, which are the key characteristics of PD that activation of caspases and apoptotic cascade

Unclear

Beginning with the individual evaluation (clinical, laboratory and electrophysiology) and the workplace obtained by individual samples of anesthetist in general hospitals in Veneto from 1990 to 1999.

unclear.

The excessive exposure to the subject's anesthetic gases may have exacerbated parkinson's disease, given the limited evidence from human studies and sufficient evidence from laboratory studies.

Unclear.

The research was carried out by a team. No repeat and no repetition

Unclear

Due to insufficient data from human studies

Yes. To the results, the conclusion was appropriate

Yes, at least for the personnel in the operating room of family history of Parkinson's disease or tremors, mood disorders, a bronchial asthma and high blood pressure (use drug like beta blocker or calcium channel blocker) are not likely to lead to a nonoccupational disease. There is no history of chemicals, rural living or use of water contaminated with pesticides. The patient is a smoker and a moderate drinker, but in theory that practices protect him from the disease of Parkinson (Mastrangelo et al., 2013).

This case report want to know about how an anesthetic gasses are relatively 
rarely associated with Parkinson's disease in several epidemiological studies. However, exposure in workplace to inhaled gases (nitrous oxide, halothane, isoflurane, levoflurane) with the risk of Parkinson's disease have been related by a number of recent mechanistic studies. It confirmed the assumption of an association between anaesthetic gas exposure and Parkinson's disease risk with a little evidence (Mastrangelo et al., 2013).

\section{DISCUSSION}

Sevoflurane is the first choice of inhaled gases for general anaesthesia because it has a more rapid of induction, lower effect of airway irritation, respiratory depression, and arrhythmia potential than the other anaesthetic gases. Sevoflurane is often combined with other anesthetic gases for example nitrous oxide for analgesic effects and desflurane for maintenance of anesthesia. According to some literature, health effect of sevoflurane can be a nephrotoxin and hepatotoxicity because of chronic exposure in occupational health. The neurotoxicity of sevoflurane is unclear because there have not a specific effect of sevoflurane exposure but some researcher believe that sevoflurane has be a trigger effect to $\beta$ accumulation like in Alzheimer's disease. In the case study, Parkinson's disease as multifactorial causes have a limited correlation with sevoflurane exposure since the level of HFIP above a normal reference. It remains unclear because limited evidence said that sevoflurane triggers a Parkinson's disease

Formation of free radicals was one of the effects induced by long-term exposure to sevoflurane. It is necessary to preserve antioxidants by taking antioxidant supplements in order to resolve this problem. Pathogenic processes associated with cancer, degeneration disease, cardiovascular disease, which are the responsibility of free radicals, must also be prevented and may boost the immune function of anaesthesia workers who are directly, especially in epidemiology study (Mastrangelo et al., 2013).

Sevoflurane will be around 2-5 percent metabolism to a metabolite, fluoroacetic acid in the liver by a particular enzyme of cytochrome P450 (2E1). This particular metabolite has been discovered to alter microsomal liver proteins. subsequently function as hapten, activating antigens for an immune-mediated antibody response. With acyl halides attached to liver proteins, the antibody will react to hapten. In several case, like paediatric anaesthesiologists who were regularly exposed to halothane, the same autoantibodies were identified, indicating that these CYP2E1 antibodies do not have a pathogenic function. Although this response was unusual due to the low percentage of metabolized sevoflurane, but it still has health effect risk (Edgington, Muco and Maani, 2007; Hemmings and Egan, 2019).

Waste anaesthetic gases can cause health effect in anaesthesiologists that have chronic exposure, such as DNA damage and increased micronucleus. In addition, oxidative stress is often correlated with anaesthetic gas waste since it causes lipid peroxidation, DNA oxidative damage, and antioxidant protection system damage in such a way that genotoxicity and mutagenicity in anaesthesiologists. However, low occupational exposure to sevoflurane did not show a major impact on the peripheral blood lymphocytes of operating room workers, but further research in the long-term are warranted (Lucio et al., 2018; zhimin ji et al., 2020).

long term exposed inhaled anaesthesia (Türkan, Aydin and Sayal, 2005).

Sevoflurane induced apoptosis and elevated levels of the level-site amyloid precursor protein-cleaving enzyme and $\mathrm{A} \beta$. In exchange, Sevoflurane stimulated caspase, which raised the levels of amyloid precursor protein and $A \beta$ at the enzyme breakdown site. Further apoptosis is caused by the rise in $\mathrm{A} \beta$ levels (Dong et al., 2009). 
Minor injury is characterized by a small increase in aminotransferase serum activity, while fulminant hepatic failure is associated with a substantial increase in liver enzyme activity and bilirubin levels, resulting in extreme liver necrosis. The study showed that some liver function biomarkers in the non-exposed group were lower than in the exposed group, especially aspartateaminotransferase, alanine aminotransferase, and gamma glutathione $\mathrm{S}$ transferase (Neghab et al., 2020).

There are two suspected mechanisms for the potential nephrotoxic activity of sevoflurane. The metabolite, fluoroacetic acid, which has shown nephrotoxicity as well as hepatotoxicity, is the first element. The second is compound $\mathrm{A}$ 's formation. Compound $\mathrm{A}$ is another fluorinated substance formed by an exothermic reaction between the absorbents of sevoflurane and carbon dioxide used in anesthetic delivery systems, which in animal studies can reportedly trigger mild and reversible injury. The theoretical risk of nephrotoxicity caused by compound $\mathrm{A}$ in humans can be time-dependent on dosage and exposure (Edgington, Muco and Maani, 2007).

Compound A (fluoromethyl-2,2difluoro-1-[trifluoromethyl] vinyl ether) is the result of the metabolism of sevoflurane, formed by its interaction with carbon monoxide absorbents. The mechanism leading to renal toxicity is still debated, with the renal cysteine conjugate $\beta$-lyase pathway (involved in compound $\mathrm{A}$ biotransformation). Human beings may be less prone to compound A renal toxicity than rats if this pathway is responsible. Human studies have shown that long exposures ( 8 hours) to sevoflurane and low fresh gas flow rates can lead to substantial output of compound A. A low risk of biochemical changes in kidney injury occurs when the flow is low from sevoflurane administration (Hemmings and Egan, 2018).

As far as their demographic characteristics concerned, no major variations between the revealed and referent subjects were noted. Furthermore, none of the studied subjects had a history of hepatotoxic and/or nephrotoxic that caused by material exposure. The result was that the biomarker of renal function in the exposed group was significantly different from the non-exposed group, particularly in the serum creatinine, kidney injury molecule-1, and calcium (Neghab et al., 2020).

Recommended exposure limit values of $2 \mathrm{ppm}$ have been recommended by NIOSH for all halogenated agents, including sevoflurane and $25 \mathrm{ppm}$ for nitrous oxide. While biological exposure indices levels were not calculated for these anaesthetic gases by ACGIH and $3.6 \mu \mathrm{g} / 1$ for sevoflurane, respectively, based on the NIOSH exposure limit of $2 \mathrm{ppm}$ (Hoerauf et al., 1996, 1999; Neghab et al., 2020).

The degree of exposure to sevoflurane depends on a variety of parameters, including the absence or existence of sufficient ventilation and scavenging systems in the operating room, the form of operation, the extent of anaesthesia face mask leaks during anaesthetic gas administration, cylindrical leakage, whether gas leakage from the anaesthetic machine is regularly verified or not. In this case, dangerous working practices such as triggering the flow of anaesthetic gas before applying a mask to the patient's face or closing the flow of anaesthetic gas after removing a face mask and improperly fitting face masks also play an important role (Neghab et al., 2020).

Accorsi et al., 2005 examined operating room workers post-shift urine by gas chromatography-mass spectrometry coupled. Subjects' levels of urinary anaesthetic gases ranged from 0.4 to 1415.9 $\mu \mathrm{g} / \mathrm{l}$ for nitrous oxide, 0.0 to $36 \mu \mathrm{g} / \mathrm{l}$ for isoflurane, and 0.0 to $46 \mu \mathrm{g} / 1$ for sevoflurane. Similarly, the concentration of anaesthetic gases in the urine of forty workers was measured by Al-Ghanem et al. The mean urinary concentrations of nitrous oxide, isoflurane and sevoflurane were 
respectively $1234, \quad 3.75$ and $4.3 \mu \mathrm{g} / 1$ (Hoerauf et al., 1999).

At the beginning of an operating room shift or a work shift, operating room personnel exposed to sevoflurane during the previous work day had accumulated high HFIP values in their urine, indicating that 24 hours was not sufficient for HFIP elimination. As for Sev-U, our findings indicate that peaks of exposure in the end operating room session is especially influenced by this biomarker $(2.8 \mathrm{~h})$. The study showed there were a statistically significant correlation between sevoflurane urine and HFIP. The variation factor can be influenced by the biological factors, which tends to be greater even at minimal exposure (with sevoflurane exposure under $1 \mathrm{ppm})$, as well as by the presence of a group of subjects with low Sev-U but relatively high HFIP levels, presumably as exposure from the day before due exposure from the previous day (Scapellato et al., 2014).

Based on the results of this analysis, the measured urinary biomarker concentrations according to the workplace exposure in 2 and $0.5 \mathrm{ppm}$ were 318 and $131 \mathrm{mg} / \mathrm{L}$ for metabolite of sevoflurane (lower $95 \%$ CL: 133 and $72 \mathrm{mg} / \mathrm{L}$ respectively) and 3.7 and $2.1 \mathrm{mg} / \mathrm{L}$ for sevoflurane urine (lower $95 \%$ CL: 2.0 and $1.4 \mathrm{mg} / \mathrm{L}$ respectively). The biological equivalent concentrations of Imbriani et al for urinary HFIP were 488 and $160 \mathrm{mg} / \mathrm{L}$, according to safe value of NIOSH exposure for airborne sevoflurane of 2 and $0.5 \mathrm{ppm}$, which some researchers proposed as a particular measure of occupational exposure to sevoflurane. Different HFIP values of $800 \mathrm{mg} / \mathrm{L}$ and $2772.7 \mathrm{mg} / \mathrm{L}$ for exposure to sevoflurane at $2 \mathrm{ppm}$. At the end of the operating session, the other study had substantial peak levels of sevoflurane exposure; the values were slightly lower $(1.9$ and $1.3 \mathrm{mg} / \mathrm{L}$ for 2 and $0.5 \mathrm{ppm}$ environmental sevoflurane exposure, respectively) (Scapellato et al., 2014).

Sevoflurane exposure to HFIP was more stable, with a longer half-life than the urinary sevoflurane biomarker (2.8 and 19 hours, respectively, for sevoflurane and HFIP). However, this value indicates several factors that can affect sevoflurane metabolism such as smoking, alcohol consumption and genetic metabolic polymorphisms. HFIP is produced from the metabolism of the CYP2E1 enzyme, where its function can be established by smoking and alcohol habits (Scapellato et al., 2014).

In addition to monitoring, according to a study conducted by Jenifer et al., environmental monitoring with multicapillary column-ion mobility spectrometry (MCC-IMS) method is also needed. There was a higher risk of turbulent flow compared to laminar flow in the operating room (Herzog-Niescery et al., 2015; Kunze et al., 2015; Neisi et al., 2019).

Due to the hazards posed by sevoflurane, it is possible to undertake a risk assessment, thus possible threats to health conditions can be anticipated. Exposure to anaesthetic gases in the workplace damage operating room personnel. Health care and environmental control, such as anaesthesia equipment maintenance, breathing system efficacy and anaesthetic gas removal procedures, and regular staff training are also highly recommended (Dehghani et al., 2020).

In order to develop an effective workplace, monitoring of occupational hazards for anaesthetists who are exposed on a daily basis is important to minimizes risks and generates a successful anaesthesiology practice. This will result in less absenteeism, better patient care, and better improvement of the anaesthesiologist's quality of life (Hoerauf et al., 1999; Volquind et al., 2013).

\section{CONCLUSION}

Sevoflurane is an inhalational anaesthetic agent that is used to induce and maintain the patient under anaesthesia during surgery. Health effects of sevoflurane as hepatotoxic, nephrotoxic and neurotoxic in the human body pose as a 
health risk for anaesthesiologist. We need to environmental and biological monitoring to create a safe and healthy workplace. We need more data to discover about a specific monitoring to supervise each anaesthesiologist that has sevoflurane exposure.

\section{REFERENCE}

Accorsi, A. et al. (2005) 'Urinary sevoflurane and hexafluoroisopropanol as biomarkers of lowlevel occupational exposure to sevoflurane', International Archives of Occupational and Environmental Health, 78(5), pp. 369-378. doi: 10.1007/s00420-0040580-8.

Brioni, J. D. et al. (2017) 'A clinical review of inhalation anesthesia with sevoflurane: from early research to emerging topics', Journal of Anesthesia, 31(5), pp. 764-778. doi: 10.1007/s00540-017-2375-6.

Dalagkozi, P. et al. (2018) 'The Effects of Exposure of Health Care Professionals to Volatile Anesthetic Gases', in. doi: 10.1007/978-3-319-70548-4_574.

Dehghani, F. et al. (2020) 'Probabilistic health risk assessment of occupational exposure to isoflurane and sevoflurane in the operating room', Ecotoxicology and Environmental Safety, 207(May 2020), p. 111270. doi: 10.1016/j.ecoenv.2020.111270.

Dong, Y. et al. (2009) 'The common inhalational anesthetic sevoflurane induces apoptosis and increases $\beta$ amyloid protein levels', Archives of Neurology. doi: 10.1001/archneurol.2009.48.

Edgington, T. L., Muco, E. and Maani, C. V. (2007) 'Sevoflurane StatPearls - NCBI Bookshelf', xPharm: The Comprehensive Pharmacology Reference, pp. 1-4.

Hemmings, H. C. and Egan, T. D. (2018)
Pharmacology and physiology for anesthesia: Foundations and clinical application, Pharmacology and Physiology for Anesthesia: Foundations and Clinical Application. doi: 10.1016/C2014-0-04139-1.

Hemmings, H. C. and Egan, T. D. (2019) Pharmacology and Physiology for Anesthesia_ Foundations and Clinical Application-Elsevier (2018).pdf.

Herzog-Niescery, J. et al. (2015) 'Occupational chronic sevoflurane exposure in the everyday reality of the anesthesia workplace', Anesthesia and Analgesia, 121(6), pp. 1519-1528. doi: 10.1213/ANE.000000000000101 5.

Hoerauf, K. H. et al. (1996) 'Occupational exposure to sevoflurane and nitrous oxide in operating room personnel', International Archives of Occupational and Environmental Health, 69(2), pp. 134-138. doi: $10.1007 / \mathrm{s} 004200050127$.

Hoerauf, K. H. et al. (1999) 'Occupational exposure to sevoflurane during sedation of adult patients', International Archives of Occupational and Environmental Health, 72(3), pp. 174-177. doi: $10.1007 / \mathrm{s} 004200050357$.

İnan, G. and Özköse Şatirlar, Z. (2015) 'Alzheimer disease and anesthesia', Turkish Journal of Medical Sciences. doi: 10.3906/sag-140740.

Kubota, Y. (1992) 'Comparative Study of Sevoflurane with Other Inhalation Agents', (Table 3), pp. 118-124.

Kunze, N. et al. (2015) 'Multi-capillary column-ion mobility spectrometry (MCC-IMS) as a new method for the quantification of occupational exposure to sevoflurane in anaesthesia workplaces: An observational feasibility study', Journal of Occupational Medicine 
and Toxicology. doi: 10.1186/s12995-015-0056-7.

Lucio, L. M. C. et al. (2018) 'Occupational hazards, DNA damage, and oxidative stress on exposure to waste anesthetic gases', Brazilian Journal of Anesthesiology. doi: 10.1016/j.bjan.2017.05.001.

Mastrangelo, G. et al. (2013) 'Exposure to anesthetic gases and Parkinson's disease: A case report', $B M C$ Neurology, 13. doi: 10.1186/14712377-13-194.

Molina Aragonés, J. M. et al. (2016) 'Occupational exposure to volatile anaesthetics: A systematic review', Occupational Medicine, 66(3), pp. 202-207. doi: $10.1093 /$ occmed/kqv193.

Neghab, M. et al. (2020) 'Toxic responses of the liver and kidneys following occupational exposure to anesthetic gases', EXCLI Journal, 19, pp. 418429. doi: 10.17179/excli2019-1911.

Neisi, A. et al. (2019) 'Investigation of health risk assessment sevoflurane on indoor air quality in the operation room in Ahvaz city, Iran', Toxin Reviews. doi: 10.1080/15569543.2018.1434796.

Scapellato, M. L. et al. (2014) 'Biomonitoring occupational sevoflurane exposure at low levels by urinary sevoflurane and hexafluoroisopropanol', Toxicology Letters, 231(2), pp. 154-160. doi: 10.1016/j.toxlet.2014.10.018.

Türkan, H., Aydin, A. and Sayal, A. (2005) 'Effect of volatile anesthetics on oxidative stress due to occupational exposure', World Journal of Surgery. doi: 10.1007/s00268-0047658-z.

Volquind, D. et al. (2013) 'Occupational Hazards and Diseases Related to the Practice of Anesthesiology', Revista Brasileira de Anestesiologia, 63(2), pp. 227-232. doi: $10.1016 / \mathrm{S} 0034-$ 7094(13)70221-6.

Zhimin ji, Wanjun Wu, Fan zhou, Junfang $\mathrm{Hu}$, Qiuping $\mathrm{Xu}$, Weibin Yang, Xueyong Peng, XInguo Wang, Cheng Zhang, L. L. (2020) 'Effects of Sevoflurane Exposure on Apoptosis and Cell Cycle of Peripheral Blood Lymphocytes, and Immunologic Function', $B M C$ Anesthesiology. Available at: https://doi.org/10.21203/rs.3.rs139150/v1. 